\title{
Secondary metabolites from the resins of Aloe vera and Commiphora mukul mitigate lipid peroxidation
}

\author{
NAJEEB UR REHMAN \\ SAMIA AHMED AL-RIYAMI \\ HIDAYAT HUSSAIN \\ AMJAD ALI \\ ABDUL LATIF KHAN* \\ AHMED AL-HARRASI* \\ Natural \& Medical Sciences \\ Reasearch Center \\ University of Nizwa \\ Nizwa, Sultanate of Oman
}

Accepted January 17, 2019

Published online April 2, 2019

\begin{abstract}
Oxidative stress is often considered detrimental for cellular processes and damaging for the lipid bi-layer. Counteracting such stresses with the aid of nature-based chemical constituents can be an ideal therapeutic approach. The current study aimed to investigate the chemical constituents of resins derived from the well-known Aloe vera and less known Commiphora mukul trees and their effect in mitigating the lipid peroxidation (LPO) process. The bio-guided isolation of bioactive fractions from both resins afforded 20 chemical constituents (17 from A. vera and 3 from C. mukul). These compounds belonged to anthraquinones, anthraquinone glycosides, quinones, coumarins, polypodane-type terpenoids and benzene derivatives. Major chemical constituents of the resins of $A$. vera and C. mukul were from the classes of quinones and terpenoids. Feroxidin $(4$, from $A$. vera) showed slightly higher inhibition $\left(I C_{50}=201.7 \pm 0.9 \mu \mathrm{mol} \mathrm{L}^{-1}\right)$ than myrrhanone C (18, from C. mukul: $\left.I C_{50}=210.7 \pm 0.0 \mu \mathrm{mol} \mathrm{L}^{-1}\right)$ and methyl 3-(4-hydroxyphenyl) propionate from A. vera (13, $\left.I C_{50}=232.9 \pm 0.2 \mu \mathrm{mol} \mathrm{L}^{-1}\right)$ compared to the other compounds. Structure-activity relationship showed that the existence of hydroxyl, methoxy and ether groups might play a major role in countering oxidative stress. To the best of our knowledge, anti-LPO activities of compounds 1-4, 14, 18 and 20 are reported for the first time. Such chemical constituents with high anti-lipid peroxidation activity could be helpful in synthesizing candidate drugs.
\end{abstract}

Keywords: Aloe vera, Commiphora mukul, anti-LPO, feroxidin, myrrhanone $\mathrm{C}$

Indigenous knowledge of medicinal plant and recipes is still being practiced throughout the world, e.g., in the Middle East $(1,2)$. Though there are numerous studies that elucidate the bioactive role of medicinal plants, their fractions and pure metabolites, little is known about pure metabolites from the resins and their anti-lipid peroxidation potentials.

\footnotetext{
*Correspondence, e-mails: aharrasi@unizwa.edu.om; latifepm78@yahoo.co.uk
} 
In the current study, we aimed to evaluate and understand the anti-lipid peroxidation potential of fractions and pure metabolites from economically and ecologically important resinous medicinal plants of Oman. In this regard, two resins of Aloe vera (A. vera) and Commiphora mukul (C. mukul) were selected because of their traditional uses and fewer studies of anti-lipid peroxidation. A. vera has been reported to be used in anti-aging, anticancer, antiinflammatory, antibacterial, antioxidant, antifungal, antiviral and antiseptic treatments (3). In addition, it is employed for preparation of cosmetic products, skin lotions, purgatives, to treat arthritis, asthma, Crohn's disease, ulcerative colitis, ulcers, acne, psoriasis, eczema, frostbite, burns, cold and sores (3, 4). Among its metabolites, previous investigations revealed isolation of two new C-glucosyl chromones with striking activities against the enzyme urease, DPPH antioxidant activity and cytotoxicity against the breast cancer cell line (5).

Commiphora (Burseraceae) contains approximately 190 species mostly distributed in southern Arabia, India and Sri Lanka (6). It has been reported that the gum resin of $C$. mukul Hook. was practiced in traditional medicines of India and many Arabian countries as an anti-inflammatory, anti-bacterial, anti-coagulant, anti-obese and anti-atherosclerosis agent (7). Interestingly, previously described compounds from the resin of $C$. mukul demonstrated anti-inflammatory and analgesic effects (6). Moreover, some isolates were used as pain killers in addition to their inhibitory potential towards nitric oxide production $(6,8)$. Our previous efforts on searching the bioactive components from $C$. mukul resulted in isolation of three compounds: myrrhanone C (18), myrrhanone B (19) and myrrhanol B (20), which exhibited antiproliferative activity against MDA-MB-231 (breast cancer cell lines) (8). Herein, we have isolated chemical constituents with anti-lipid peroxidation potential from the resins of two plants (A. vera and $C$. mukul). In the current study, an in vitro approach was adopted to initially screen the different fractions of the resins obtained from the plants and then follow them up with comprehensive chromatographic and spectroscopic techniques to obtain pure constituents.

\section{EXPERIMENTAL}

\section{General experimental procedures}

TLC (thin layer chromatography) plates were used under UV light at 254 and $366 \mathrm{~nm}$; silica gel pre-coated Al sheets (60F-254, Merck, Germany) were used. Ceric sulphate spray was used as a dyeing reagent followed by heating $\left(110-130^{\circ} \mathrm{C}\right)$ through a heat gun. Bruker ${ }^{1} \mathrm{H}$ NMR (multinuclear and multidimensional) operating at $600 \mathrm{MHz}\left(150 \mathrm{MHz}\right.$ for $\left.{ }^{13} \mathrm{C}\right)$ with CryoProbe Prodigy (chemical shift, $\delta$ in ppm, with tetramethyl sylane, TMS, as internal standard, $J$ value in $\mathrm{Hz}$ ) was used (Bruker, USA). Bruker ATR Tensor 37 spectrophotometer was used for infrared spectra $\left(\mathrm{cm}^{-1}\right)$ and a mass spectrometer (Waters Quattro Premier XE, Waters, USA) was used for the determination of molecular masses of the compounds. All solvents used for isolation were properly distilled.

\section{Sample collection and fractionation}

Air dried ground materials of resins of A. vera (2016) and C. mukul (2014) were purchased from the local market (Souq) in Nizwa, Sultanate of Oman, and identified by the plant taxonomist Mr. Saif Al-Hatmi at the Oman Botanical Garden Muscat, Oman. Voucher 


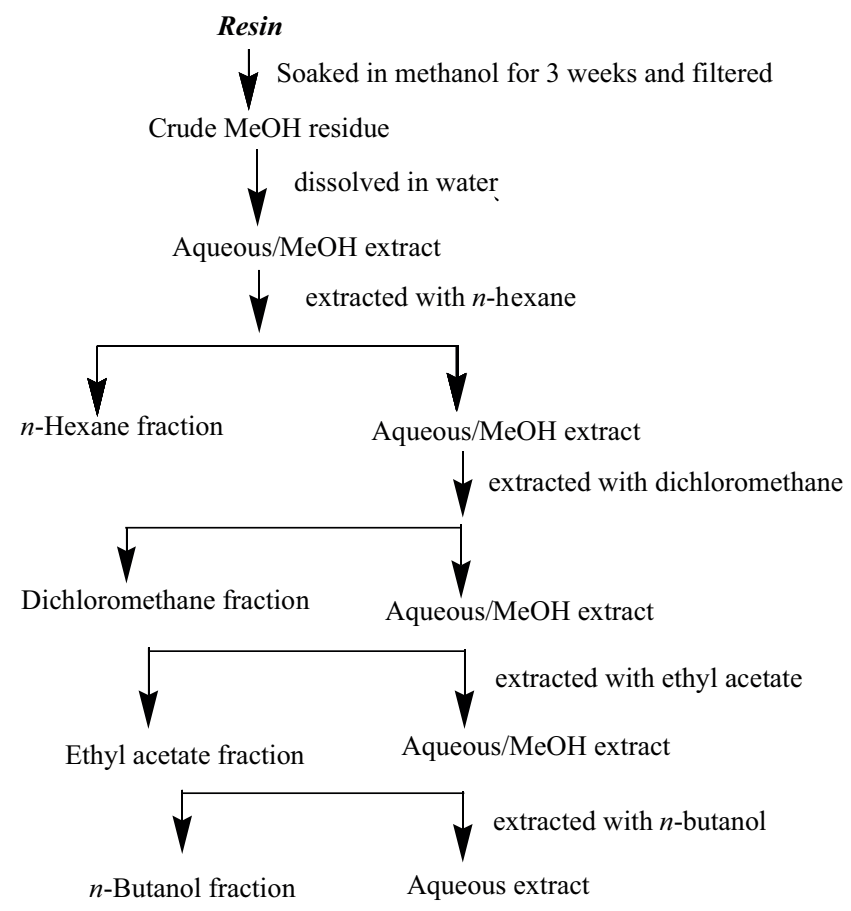

Fig. 1. Fractionation scheme for solvent-solvent extraction of the resins from Commiphora mukul and Aloe vera.

specimen of $A$. vera (No. AFS-08/2016) was deposited in the Oman Botanical Garden herbarium, Muscat, while C. mukul (No. CMS-03/2014) was deposited in the herbarium of the Department of Biological Sciences and Chemistry, University of Nizwa, Oman. General fractionation scheme for solvent-solvent fractionation of both resins is given in Fig. 1. Different fractions were then subjected to initial screening for anti-lipid peroxidation. Upon positive results, the extracts were subjected to column chromatography.

\section{Extraction, isolation and identification of compounds from A. vera resin (1-17)}

Air dried powdered material $(1.2 \mathrm{~kg})$ of $A$. vera resin was carefully extracted with methanol $(3 \mathrm{~L})$ at room temperature. Evaporation of methanol under reduced pressure at room temperature yielded the crude methanol extract, which was further fractionated into $n$-hexane, dichloromethane $\left(\mathrm{CH}_{2} \mathrm{Cl}_{2}\right)$, ethyl acetate (EtOAc), $n$-butanol and aqueous fractions (5). Dichloromethane fraction was subjected to silica gel column chromatography (CC) (0.063-0.210 mm, Merck), using $n$-hexane, $n$-hexane/ethyl acetate, ethyl acetate, ethyl acetate/methanol and pure methanol to afford ten fractions $\left(\mathrm{F}_{1-10}\right)$. Fraction $\mathrm{F}_{4}(2.0 \mathrm{~g})$ was subjected to further CC using EtOAc/n-hexane (70:30 to 90:10) as eluent to afford compounds 1-3 and 5-7. Similarly, fraction $\mathrm{F}_{2}(0.8 \mathrm{~g})$, obtained on elution of the crude material with $30-40 \%$ ethyl acetate $/ n$-hexane, was re-chromatographed using ethyl acetate $/ n$-hex- 
ane (40:60 to 80:20) as eluent and provided compounds 8-10. Repeated CC of fraction $\mathrm{F}_{3}$ using ethyl acetate- $n$-hexane (20:80 to 50:50) in gradient elution mode yielded compounds 4 and 11-13. Finally, fraction $\mathrm{F}_{1}$ was subjected to further $\mathrm{CC}$ using ethyl acetate $/ n$-hexane (10:90 to 20:80) as gradient eluent and provided compounds 14-17.

Compounds $\mathbf{1 - 1 7}$ were identified as 6'-O-coumaroylaloesin (1), aloeveraside A (2) and aloeveraside B (3) (5), feroxidin (4), aloinoside B (5), 10-hydroxyaloins A (6) and B (7), emodin (8), aloe-emodin (9), aloe-emodin-11-O-rhamnoside (10), 7-demethylsiderin (11) (9), 3-(4-hydroxyphenyl)propanoic acid (12), methyl 3-(4-hydroxyphenyl)propionate (13), 1-(2,4-dihydroxy-6-methylphenyl)ethanone (14), $p$-anisaldehyde (15), salicylaldehyde (16), $p$-cresol (17), resp., (Fig. 2), by $1 \mathrm{D}\left({ }^{1} \mathrm{H}\right.$ and $\left.{ }^{13} \mathrm{C}\right)$ and 2D (HSQC, HMBC, COESY and NEOSY) NMR and mass spectrometry.

\section{Extraction, isolation and identification of compounds from C. mukul resin (18-20)}

C. mukul resin was finely ground and extracted with methanol (3.5 L) at r.t. Vaporization of the solvent under reduced pressure gave a crude methanol residue, which was fractionated into sub-fractions with $n$-hexane, $\mathrm{CH}_{2} \mathrm{Cl}_{2}$, EtOAc, $n$-butanol and water. The $n$-hexane fraction was subjected to silica gel column chromatography $(0.063-0.210 \mathrm{~mm}$, Merck), using the $n$-hexane/ $\mathrm{CH}_{2} \mathrm{Cl}_{2}$ (70:30) system as eluent, to give compound 18. Similarly, ethyl acetate fraction was subjected to silica gel column chromatography to afford compounds 19 and 20 using an ethyl acetate- $n$-hexane (30:70) system (8).

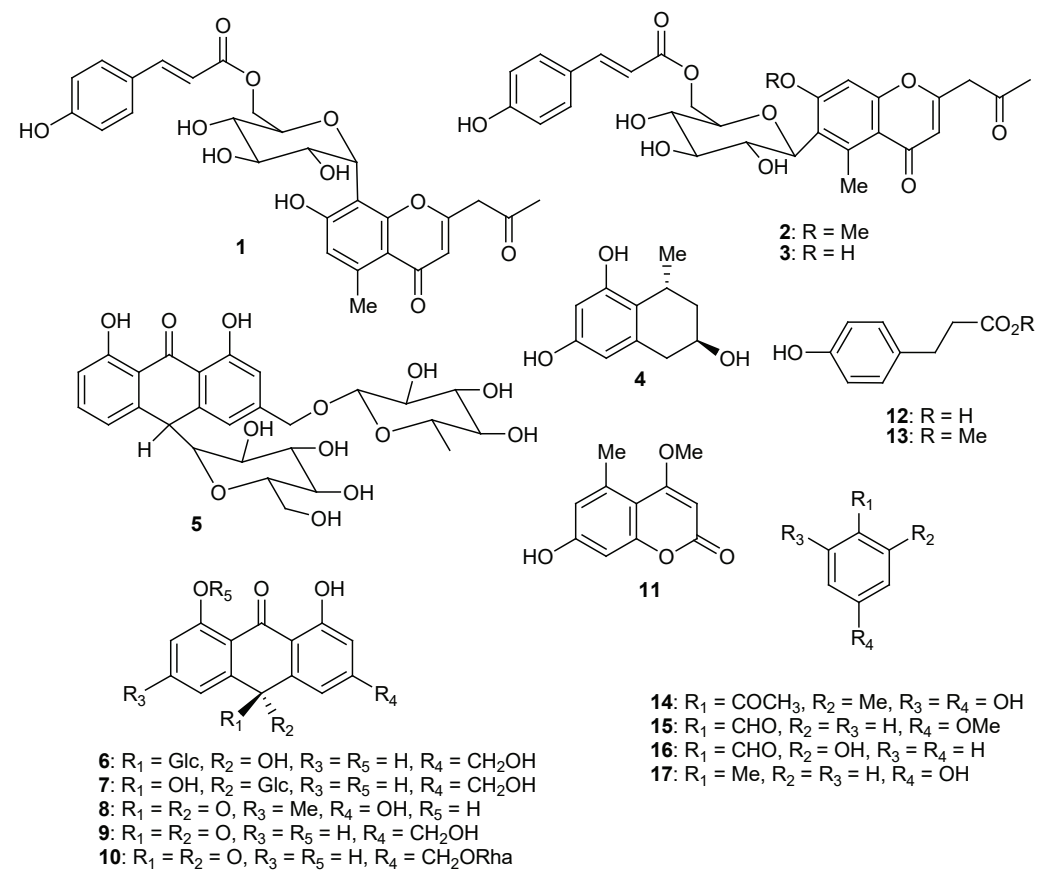

Fig. 2. Compounds isolated from Aloe vera resin $(5,9)$. 


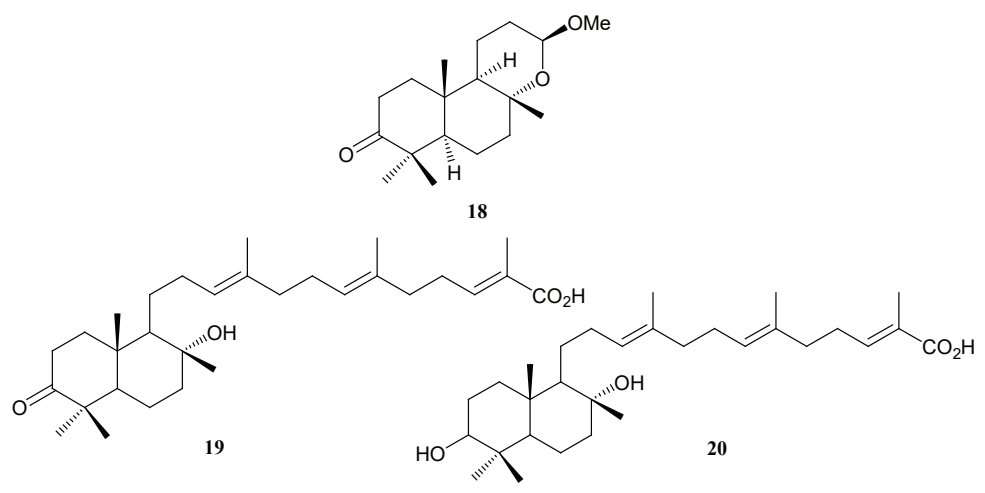

Fig. 3. Compounds isolated from Commiphora mukul resin (8).

Compounds 18-20 were identified as myrrhanone C (18), myrrhanone B (19) and myrrhanol B (20) (8) (Fig. 3) by 1D and 2D NMR spectroscopic techniques and mass spectrometry.

\section{In vitro anti-lipid peroxidation activity (LPO) of fractions and pure metabolites}

Isolated fractions and compounds in different concentrations were screened for inhibiting the LPO. This was performed using a modified method of TBARS (thiobarbituric acid reactive substances) (10). The LPO of liposome $\left(50 \mathrm{mg} \mathrm{mL}^{-1}\right.$ phosphatidyl-choline, Sigma, Germany) was initiated by adding $\mathrm{FeCl}_{3}\left(200 \mu \mathrm{L}, 0.001 \mathrm{mmol} \mathrm{L}^{-1}\right), \mathrm{KCl}\left(200 \mu \mathrm{L}, 300 \mathrm{mmol} \mathrm{L}^{-1}\right)$ and test compounds ( $50 \mu \mathrm{L}, 5$ to $\left.50 \mu \mathrm{g} \mathrm{mL}^{-1}\right)$. This was followed by the addition of ascorbic acid $\left(125 \mu \mathrm{L}, 0.001 \mathrm{~mol} \mathrm{~L}^{-1}\right)$ to the reaction mixture and incubation for $30 \mathrm{~min}\left(37^{\circ} \mathrm{C}\right)$. Trichloroacetic acid and thiobarbituric acid ( $1 \%$ TCA, $0.38 \%$ TBA) were added to the final reaction mixture and the glass vials were kept in a water bath $\left(95^{\circ} \mathrm{C}\right)$ for 1 hour. Alteration in pink color was noted on ELISA at $535 \mathrm{~nm}$. A control without pure compounds was employed as a negative control while butyl hydroxy toluene (BHT) was used as a positive control. All chemicals used were of Merck KgaA, Germany. Percent inhibition was noted. The experiment was repeated three times.

\section{Statistical analysis}

Data was analyzed by one-way ANOVA analysis in GraphPad Prism (v6.01, Benferroni test) with a specific $I C_{50}$ package, using non-linear regression (dose-response inhibition) diagnoses by $R$-square goodness-of-fit and D'Agostino-Pearson omnibus normality test. In addition, Duncan's multiple range (DMRT) test using $p<0.05$ was also performed for the replicates through SAS (9.1; Cary, NC, USA).

\section{RESULTS AND DISCUSSION}

\section{Phytochemical investigations of A. vera and C. mukul resins}

We have isolated and characterized 20 different compounds belonging to different classes such as polypodane-type triterpenes, chromones, anthrones, anthraquinones, anthraquinones glycosides and benzene derivatives. 


\section{Anti-lipid peroxidation activity of pure chemical constituents}

To assess the anti-lipid peroxidation potential of the twenty isolated compounds, they were initially screened. Compounds $\mathbf{1 - 4 , 6 , 9}$ and $\mathbf{1 2 - 1 7}$ from the resin of $A$. vera, and compounds 18 and 20 from C. mukul showed promising anti-lipid peroxidation activity, still lower than that of BHT (Table I). The lowest $I C_{50}$ values were found for feroxidin (4) and myrrhanone $C$ (18), followed by methyl 3-(4-hydroxyphenyl)propionate (13), 1-(2,4-dihydroxy-6-methylphenyl)ethanone (14) and $p$-anisaldehyde (15).

Aloe vera resin. - Compound 4 identified in A. vera exhibited significantly $(p<0.0079)$ higher anti-LPO effect $\left(I C_{50}=201.7 \pm 0.9 \mu \mathrm{mol} \mathrm{L}^{-1}\right)$ among all active constituents, though the inhibition percentage was significantly lower than that of the positive control (BHT: $I C_{50}=$ $\left.58.4 \pm 0.8 \mu \mathrm{mol} \mathrm{L}^{-1}\right)$. Compound 13 also showed significantly $(p<0.0262)$ higher inhibition $\left(I C_{50}=232.9 \pm 0.2 \mu \mathrm{mol} \mathrm{L}^{-1}\right)$ compared to other compounds isolated from $A$. vera resin. The $I C_{50}$ for compounds 14 and 15 was calculated as $269.1 \pm 0.7$ and $289.1 \pm 0.6 \mu \mathrm{mol} \mathrm{L} \mathrm{L}^{-1}$, resp. On the other hand, the remaining compounds $(1-3,6,9,12,16$ and 17) showed lower anti-lipid peroxidation activity.

The promising lipid peroxidation inhibitory activity exhibited by the compounds isolated from A. vera may substantiate its use in traditional medicine. Our previous study reported the isolation of two active compounds, aloeverasides A (2) and B (3), from the

Table I. Anti-lipid peroxidation activity of isolated compounds

\begin{tabular}{cc}
\hline Compd. & $\left.I C_{50}(\mu \mathrm{mol} \mathrm{L})^{-1}\right)$ \\
\hline $\mathbf{1}$ & $476.4 \pm 0.9$ \\
$\mathbf{2}$ & $469.5 \pm 0.4$ \\
$\mathbf{4}$ & $432.1 \pm 0.6$ \\
$\mathbf{6}$ & $201.7 \pm 0.9$ \\
$\mathbf{9}$ & $762.3 \pm 0.1$ \\
$\mathbf{1 2}$ & $801.8 \pm 0.8$ \\
$\mathbf{1 3}$ & $868.1 \pm 0.9$ \\
$\mathbf{1 4}$ & $232.9 \pm 0.2$ \\
$\mathbf{1 5}$ & $269.1 \pm 0.7$ \\
$\mathbf{1 6}$ & $289.1 \pm 0.6$ \\
$\mathbf{1 7}$ & $701.8 \pm 1.0$ \\
$\mathbf{1 8}$ & $713.9 \pm 2.1$ \\
$\mathbf{2 0}$ & $210.7 \pm 0.0_{1}$ \\
Control (BHT) & $522.4 \pm 0.3$ \\
\hline
\end{tabular}

BHT - butyl hydroxy toluene (positive control)

${ }^{a}$ Mean \pm SEM, $n=3$. 
resin of $A$. vera, with breast cancer cell growth inhibition, urease inhibition and antioxidant activity (5).

Commiphora mukul resin. - Among the isolated compounds from C. mukul, compound 18 displayed the highest lipid peroxidation activity $\left(I C_{50}=210.7 \pm 0.01 \mu \mathrm{mol} \mathrm{L}^{-1}\right)$, followed by compound $20\left(I C_{50}=522.4 \pm 0.2 \mu \mathrm{mol} \mathrm{L}^{-1}\right)$. Activity of compound 18 can be attributed to the presence of methoxy or ether linkage, which is absent in the other two compounds (19 and 20) (12) isolated from C. mukul resin.

\section{Structure activity relationship}

The presence of -OH groups in compound 4 may be a major feature of its promising anti-lipid peroxidation activity compared to the positive control (BHT). In addition, compound 13 showed four times higher activity than compound 12, which may be due to the presence of the methyl group instead of hydrogen in the side-chain. Among the isolated compounds 1-3, compound $\mathbf{3}$ showed slightly higher activity than $\mathbf{1}$ and $\mathbf{2}$, which is correlated with one extra-OH group attached to the benzene ring at position $\mathrm{C}-7$. Compounds $\mathbf{1}$ and $\mathbf{2}$ showed almost similar anti-lipid peroxidation activity probably because of the same functional groups.

Among phenolic compounds, the higher anti-LPO activity of compound $\mathbf{1 4}$ than that of 15-17 might be due to the presence of -OH groups attached in ortho and para positions with respect to the acetyl group. Higher activity of compound $\mathbf{1 5}$ than $\mathbf{1 6}$ can be due to the presence of the $-\mathrm{OCH}_{3}$ group in para position. The presence of $\mathrm{C}-\mathrm{O}-\mathrm{C}$ (ether) and $-\mathrm{OCH}_{3}$ groups in $\mathbf{1 8}$ is a prominent feature of its higher activity than $\mathbf{2 0}$. Our previous study suggested that compounds 18-20 showed significantly higher anti-proliferative activity in case of breast cancer cell lines, whilst they also possessed moderate $\alpha$-glucosidase and urease enzyme inhibition activities (8). Such chemical structures can help scavenge the free radicals produced during the process of lipid peroxidation $(11,13)$. Overall, the current results suggest that the presence of $-\mathrm{OH}$, ether and $-\mathrm{OCH}_{3}$ group may enhance the anti-lipid peroxidation activity. Similar conclusions were drawn previously (13). Polyhydroxylated compounds, in particular flavones, have often been known to act as antioxidants (14).

\section{Screening for in vitro lipid peroxidation of different fractions from both resins}

The in vitro LPO inhibition of different fractions of $A$. vera resin (expressed as concentration to exhibit $50 \%$ inhibition) were as follows: EtOAc fraction of $271.3 \pm 0.8 \mu \mathrm{g} \mathrm{mL}^{-1}$, followed by $n$-butanol fraction with the value of $289.6 \pm 0.4 \mu \mathrm{g} \mathrm{mL}^{-1}$ and $n$-hexane fraction with $632.9 \pm 0.7 \mu \mathrm{g} \mathrm{mL}-1$ (Table II). The anti-LPO effect of $\mathrm{CH}_{2} \mathrm{Cl}_{2}$ fraction of $C$. mukul, expressed as concentration to exhibit $50 \%$ inhibition, was $210.4 \pm 0.8 \mu \mathrm{g} \mathrm{mL}^{-1}$, followed by aqueous and EtOAc fraction with $228.4 \pm 0.8 \mu \mathrm{g} \mathrm{mL}^{-1}$ and $230.3 \pm 0.7 \mu \mathrm{g} \mathrm{mL}{ }^{-1}$, resp., whilst $n$-hexane fraction showed the value of $436.4 \pm 0.9 \mu \mathrm{g} \mathrm{mL} \mathrm{m}^{-1}$. Our results are in conformity with Ramesh et al. (2012), who studied the effects of $C$. mukul resin in lipid peroxidation and hepatic enzyme markers in diabetic rats (11).

\section{CONCLUSIONS}

The current study reports the isolation and characterization of twenty known compounds from the resins of $A$. vera and C. mukul. Among the isolated compounds, fourteen 
N. Ur Rehman et al.: Secondary metabolites from the resins of Aloe vera and Commiphora mukul mitigate lipid peroxidation, Acta Pharm. 69 (2019) 433-441.

Table II. In vitro anti-lipid peroxidation activity of different fractions of plant resins

\begin{tabular}{cc}
\hline Extract code & $\left.I_{50}(\mu \mathrm{mol} \mathrm{L})^{-1}\right)$ \\
\hline \multicolumn{3}{c}{ A. vera } \\
\hline AVHF & $632.9 \pm 0.7$ \\
AVEF & $343.3 \pm 0.8$ \\
AVBF & $271.3 \pm 0.8$ \\
AVWF & $289.6 \pm 0.4$ \\
& $473.3 \pm 0.8$ \\
\hline CMHF & \\
CMDF & $436.4 \pm 0.9$ \\
CMEF & $210.4 \pm 0.8$ \\
CMMF & $230.3 \pm 0.7$ \\
CMBF & $362.1 \pm 0.4$ \\
CMWF & $353.4 \pm 0.6$ \\
\hline
\end{tabular}

Fraction in solvent: BF - n-butanol, DF - dichloromethane, EF - ethyl acetate, HF - $n$-hexane, MF - methanol, WF - water

${ }^{\text {a }}$ Mean \pm SEM, $n=3$.

were found to be promising agents for LPO inhibition. Furthermore, activities of compounds 1-4, 14, 18 and 20 are reported here for the first time and could be promising sources of new potential antioxidant agents. From the assessment of the relationship of compound skeleton and structure with their potential to inhibit lipid peroxidation, it can be concluded that the presence and position of $-\mathrm{OH},-\mathrm{OCH}_{3}$ and ether groups in phytochemicals might play a crucial role in anti-lipid peroxidation. Among isolated compounds, 4 and 18 can be potentially used for minimizing or preventing LPO, improving the nutritional quality and prolonging the shelf life of foods and pharmaceuticals. Furthermore, the present findings reveal that resin-based chemical constituents may offer an alternative for addressing lipid peroxidation and related ailments.

Acknowledgments. - The authors thank The Oman Research Council (TRC) for its generous support through the project ORG/HSS/14/004. We are also grateful to Mr. Saif Al-Hatmi (Oman Botanical Garden, Muscat) and Dr. Syed Abdullah Gillani (Department of Biological Sciences and Chemistry, University of Nizwa, Oman) for the identification of plant samples.

\section{REFERENCES}

1. S. A. Ghazanfar and A. M. A. Al-Sabahi, Medicinal plants of northern and central Oman (Arabia), Econ. Bot. 47 (1993) 89-98; https://doi.org/10.1007/BF02862209

2. M. A. Rahman, J. S. Mossa, M. S. Al-Said and M. A. Al-Yahya, Medicinal plant diversity in the flora of Saudi Arabia 1: a report on seven plant families, Fitoterapia 75 (2004) 149-161; https://doi. org/10.1016/j.fitote.2003.12.012 
3. V. Gupta and S. Malhotra, Pharmacological attribute of Aloe vera: Revalidation through experimental and clinical studies, Ayu 33 (2012) 193-196; https://doi.org/10.4103/0974-8520.105237

4. M. Megeressa, D. Bisrat, A. Mazumder and L. Asres, Structural elucidation of some antimicrobial constituents from the leaf latex of Aloe trigonantha L.C. Leach, BMC Complement. Altern. Med. 15 (2015) 270-276; https://doi.org/10.1186/s12906-015-0803-4

5. N. U. Rehman, H. Hussain, M. Khiat, S. A. Al-Riyami, R. Csuk, H. Y. Khan, G. Abbas, G. S. AlThani, I. R. Green and A. Al-Harras, Aloeverasides A and B: Two bioactive C-glucosyl chromones from Aloe vera resin, Helv. Chim. Acta 99 (2016) 687-690; https://doi.org/10.1002/hlca.201600126

6. H. Matsuda, T. Morikawa, S. Ando, H. Oominami, T. Murakami, I. Kimura and M. Yoshikawa, Absolute stereostructures of polypodane- and octanordammarane-type triterpenes with nitric oxide production inhibitory activity from guggul-gum resins, Bioorg. Med. Chem. 12 (2004) 30373046; https://doi.org/10.1016/j.bmc.2004.03.020

7. H. Matsuda, T Morikawa, S. Ando, H. Oominami, T. Murakami, I. Kimura and M. Yoshikawa, Absolute stereostructures of polypodane-type triterpenes, myrrhanol A and myrrhanone A, from guggul-gum resin (the resin of Balsamodendron mukul), Chem. Pharm. Bull. 52 (2004) 1200-1203; https://doi.org/10.1248/cpb.52.1200

8. N. U Rehman, H. Hussain, H. Y. Khan, R. Csuk, G. Abbas, I. R. Green and A. Al-Harrasi, A norterpenoid and tripenoids from Commiphora mukul: isolation and biological activity, Z. Naturforsch. 72b (2017) 11-15; https://doi.org/10.1515/znb-2016-0062

9. E. Dagne, D. Bisrat, A. Viljoen and B. V. Wyk, Chemistry of Aloe species, Curr. Org. Chem. 4 (2000) 1055-1078; https://doi.org/10.2174/1385272003375932

10. K. S. Nagarsekar, M. S. Nagarsenkar and S. R. Kulkarni, Antioxidant and antilipid peroxidation potential of supercritical fluid extract and ethanol extract of leaves of Vitex negundo Linn., Indian J. Pharm. Sci. 73 (2011) 422-429; https://doi.org/10.4103/0250-474X.95629

11. B. Ramesh, R. Karuna, R. S. Sreenivasa, K. Haritha, M. D. Sai, B. R. Sasi and D. Saralakumari, Effect of Commiphora mukul gum resin on hepatic marker enzymes, lipid peroxidation and antioxidants status in pancreas and heart of streptozotocin induced diabetic rats, Asian Pac. J. Trop. Biomed. 2 (2012) 895-900; https://doi.org/10.1016/S2221-1691(12)60249-4

12. J. A. Francis, S. N. Raja and M. G. Nair, Bioactive terpenoids and guggulusteroids from Commiphora mukul gum resin of potential anti-inflammatory interest, Chem. Biodivers. 1 (2004) 1842 1853; https://doi.org/10.1002/cbdv.200490138

13. L. Nie, H. Song, A. He and S. Yao, Recent research progress in natural bioactive constituents against lipid metabolic diseases, Curr. Top. Med. Chem. 16 (2016) 2605-2624; https://doi.org/10.2174 /1568026616666160414124145

14. N. Cotelle, J. L. Bernier, J. P. Catteau, J. Pommery, J. C. Wallet and E. M. Gaydou, Antioxidant properties of hydroxy-flavones, Free Radic. Biol. Med. 20 (1996) 35-43; https://doi.org/10.1016/08915849(95)02014-4 